\title{
Effects of climate change on the thermal regime of a reservoir
}

Mahsa Modiri-Gharehveran

Research assistant, School of Civil Engineering, Purdue University, West Lafayette, Indiana, USA

Amir Etemad-Shahidi PhD

Senior Lecturer, Griffith School of Engineering, Gold Coast Campus,

Griffith University, Queensland, Australia
Ebrahim Jabbari PhD

Associate Professor, School of Civil Engineering, Iran University of Science and Technology, Tehran, Iran

Thermal stratification is strongly associated with hydrodynamics, and plays an important role in the dynamics of water quality and the ecosystem of stratified water bodies. Changes in the climate or hydrological conditions can alter thermal regimes. This study aims to investigate the effects of climate change on the thermal structure of a reservoir. To quantify these effects, a hydrodynamic and water quality model was applied to the Latian dam reservoir in Iran. The outputs of the Canadian global climate model version 3 for $B_{1}, A_{1} B$ and $A_{2}$ scenarios were used to obtain future (year 2100) air temperature trends. Results from these scenarios were compared with those of base conditions to investigate the effects of climate change. The maximum surface water temperature increase was about $2^{\circ} \mathrm{C}$ for the S2 scenario, which was the scenario with the highest air temperature increase $\left(5 \cdot 7^{\circ} \mathrm{C}\right)$. The increase in water temperature indicated some important effects on thermal stratification; for example, thermal gradient across the metalimnion was increased. It was also inferred that the Latian dam was severely sensitive to inflow variations as well as temperature changes.

\section{Introduction}

Global climatic changes, as defined by the US Global Change Research Act of 1990, are changes in the global environment that may alter the capacity of the earth to sustain life. Increases in the concentration of greenhouse gases due to natural and anthropogenic factors have led to substantial changes in climate in the twenty-first century (Johns et al., 2003). The rapid global temperature rise by $0.5^{\circ} \mathrm{C}$ above the long-term (1951-1980) average partly contributes to these factors (IPCC, 2001). Global warming is a response to the rising atmospheric concentrations of greenhouse gases. It has been stated that a doubling of ambient carbon dioxide has raised the worldwide air temperature by $1 \cdot 4-5 \cdot 8^{\circ} \mathrm{C}$ from the pre-industrial level (IPCC, 2001). Also, it is estimated that the mean temperature of the earth's surface will increase by as much as $6^{\circ} \mathrm{C}$ by the end of the twenty-first century (Bates et al., 2008). However, the amount of air temperature change is expected to vary significantly in different regions. The air temperature increase will be greater at higher latitudes and over land. Global warming will cause ecological and social impacts in the world that may lead to devastating consequences. As water bodies play an important role in the world, assessing the effects of global warming on water bodies has been an important issue for scientists and engineers. Also, global warming has a significant impact on the water quality and ecological characteristics of lakes and reservoirs (Wang et al., 2012). Column mixing in lakes can be strongly affected by the increased heat influx. Deep stratified lakes usually mix or turn over in spring and autumn, when the near-surface water temperature reaches $4^{\circ} \mathrm{C}$, the temperature of maximum density for water. Circulation of lakes brings the oxygen from the surface to the deeper layers and resuspends nutrients previously trapped at the bottom of lakes. Thermal stratification of lakes refers to changes in the temperature profile with depth within a lake system and is due to the change in the density of water with temperature (Moreno-Ostos et al., 2008). During periods of strong stratification, the lower portion of a lake becomes isolated from the atmosphere and the developed vertical density gradient acts as a barrier to complete mixing of the lake (Wetzel, 2001). Thermal gradients may be a consequence of external inflows or underground seepage. Without mixing to replace dissolved oxygen, the deeper water layers, lacking enough light for photosynthesis to occur, tend to have a very limited supply of oxygen. Microbial respiration can deplete the dissolved oxygen in the lower portion of lakes (Branco et al., 2009; Welch and Jacoby, 2001). The situation can be critical when it is considered that oxygen-carrying capacity is vital to support aquatic ecosystems.

The thermal/mixing regime strongly affects nutrient loadings, phytoplankton abundance and lake water chemistry in lakes and reservoirs. Hordoir and Meier (2012) found that thermal stratification changes may have an important impact on vertical nutrient fluxes and the intensity of the spring bloom in the future climate of the Baltic Sea. The consequences of changes in thermal structure in lakes will have a significant impact on fisheries, wildlife, wetlands, shoreline habitat and water quality. The effects of climate change (most likely increasing air temperature) by 2100 on the thermal structure of lakes will generally be equivalent to considerable increases in the external nutrient 
loading and then changing eutrophication states in lakes (Trolle et al., 2011).

In the present study, a two-dimensional (2D) hydrodynamic and water quality model was applied to simulate the Latian dam response to different climate change scenarios. Latian dam reservoir is one of the most important reservoirs in Iran and experiences thermal stratification in summer. In this investigation, the climate change effects on the thermal stratification of this reservoir, changes of water temperature and variations of the thermal stratification period were assessed. To quantify the thermal stratification of Latian dam reservoir, temperature and inflow rates of the Jajroud and Lavarak rivers were used as model inputs. In addition, the measured water elevation data and vertical temperature profile of the reservoir were used to validate the hydrodynamic model. Then, the calibrated and verified model was applied to evaluate the changes in the stratification of the reservoir considering the future possible conditions represented by 21 climate change scenarios.

\section{Materials and methods}

\subsection{Study site}

Latian dam ( $\left.35^{\circ} 47^{\prime} 24^{\prime \prime} \mathrm{N} ; 51^{\circ} 40^{\prime} 48^{\prime \prime} \mathrm{E}\right)$ is located about $25 \mathrm{~km}$ north-east of Tehran city in Iran (Figure 1). Latian dam is one of the most important water supply sources for residents in downstream areas, including Tehran city (population over 12 million). This impoundment was initially filled in 1968. The reservoir has a surface area of $3.3 \mathrm{~km}^{2}$ and a drainage area of $670 \mathrm{~km}^{2}$, with a mean and maximum depth of 22 and $45 \mathrm{~m}$, respectively. The average residence time of water in this reservoir is approximately 80 days. Generally, the maximum water level is $1610 \mathrm{~m}$ above sea level, corresponding to a capacity of $7.9 \times 10^{7} \mathrm{~m}^{3}$ and the minimum water level is $1554 \mathrm{~m}$, corresponding to a capacity of $0 \cdot 2 \times 10^{6} \mathrm{~m}^{3}$. Latian reservoir is fed by two major rivers, the Jajroud and Lavarak rivers. The main outlets are two bottom outlets. The upstream and surrounding landscape of the reservoir is largely mountainous and consists primarily of hills with little agricultural activity. The area is chiefly used for recreation, especially in the spring and summer.

\subsection{Model description}

In this study, CE-QUAL-W2, a 2D (longitudinal-vertical) hydrodynamic and water quality model, developed by the US Army Corps of Engineers, was used to analyse the thermal stratification of the Latian dam reservoir. A detailed description of the CE-QUAL-W2 model is given in Cole and Wells (2003). Hydrodynamic calculations include time-varying surface elevations, and horizontal and vertical distributions of temperature and water velocities. This model can be used to model basic eutrophication processes such as dissolved oxygen, temperature, nutrients, algae, organic matter and sediment relationships. As the model assumes lateral homogeneity, it is well suited for relatively long and narrow water bodies exhibiting longitudinal and vertical water quality gradients. It can be applied to rivers, lakes, reservoirs, estuaries and river basin systems. CE-QUAL-W2 has been successfully applied to numerous case studies (Afshar et al., 2012; Dai et al., 2012; Etemad-Shahidi et al., 2009; Garvey et al., 1998; Hasanloo and Etemad-Shahidi, 2011; Martin, 1988; Parsa and Etemad-Shahidi, 2010; Rangel-Peraza et al., 2012; Tillman and Cole, 1994; Zahed et al., 2008).

\subsection{Model application}

Bathymetric and geometric data of the reservoir are required to develop the computational model. Therefore, the study area was divided into 21 horizontal segments and 34 vertical layers (Figure

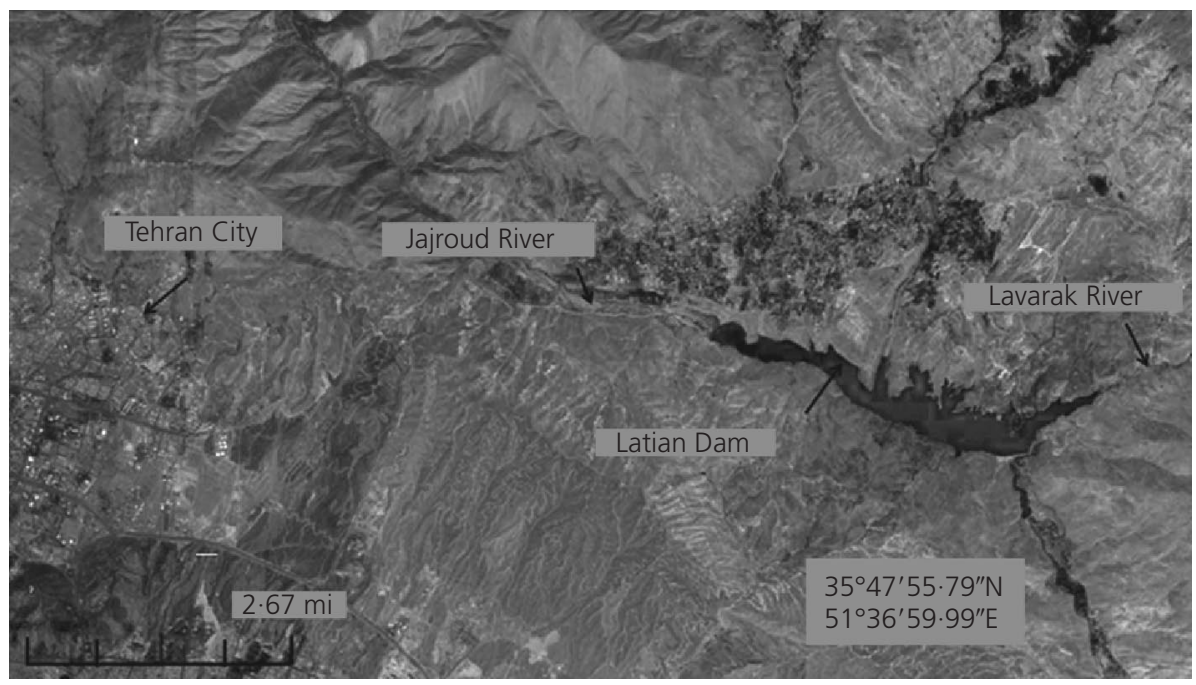

Figure 1. Illustration of Latian reservoir showing the location and monitoring sites 
2). Boundary conditions categorised into three different groups were set up for the model. The first group was meteorological variables, the second category was various incoming and outgoing flows and the last one was the water temperature of the inflow. In this study, water temperatures at different depths of the reservoir on 21 April 2008 were selected to set up as the initial condition (Figure 3).

\subsection{Model calibration and verification}

Calibration of the water budget (or water surface elevation) is usually the first step in the sequence of calibration processes in lake and reservoir modelling. The next steps are the calibration of the temperature and water quality, respectively. The measured water level fluctuations and water temperature during the year 2008 were used for model calibration. The water budget was controlled by comparing the predicted elevations with the observed elevations. A comparison between predicted and measured water surface elevations is shown in Figure 4. The difference in water surface elevation was less than $\pm 0.7 \mathrm{~m}$ during all simulation periods. In addition, the mean of differences in water surface elevation was $0 \cdot 16 \mathrm{~m}$. So the model can simulate reservoir hydrodynamics successfully.

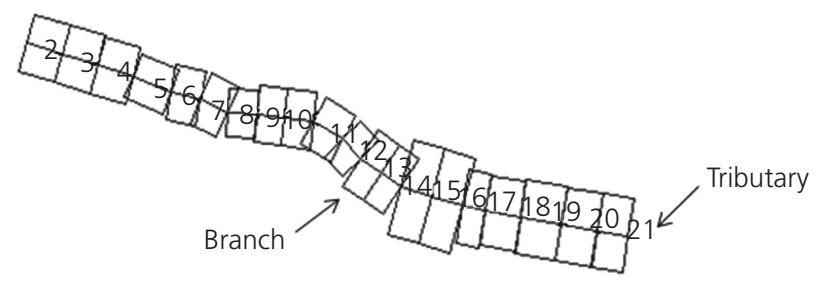

(a)

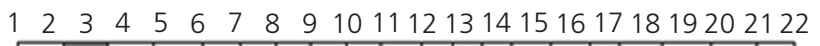

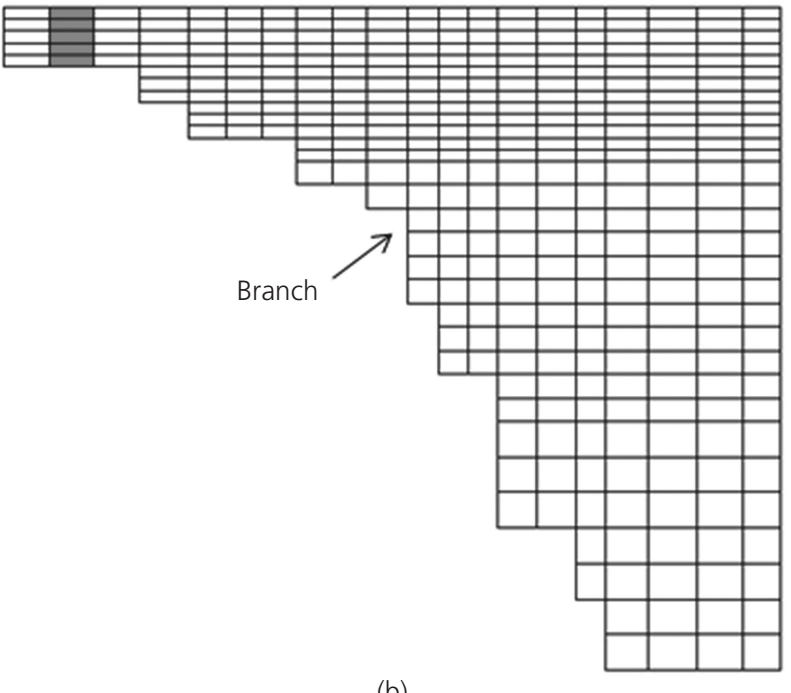

(b)

Figure 2. Model grid: (a) top view $(x-y)$ and (b) side view (y-z)

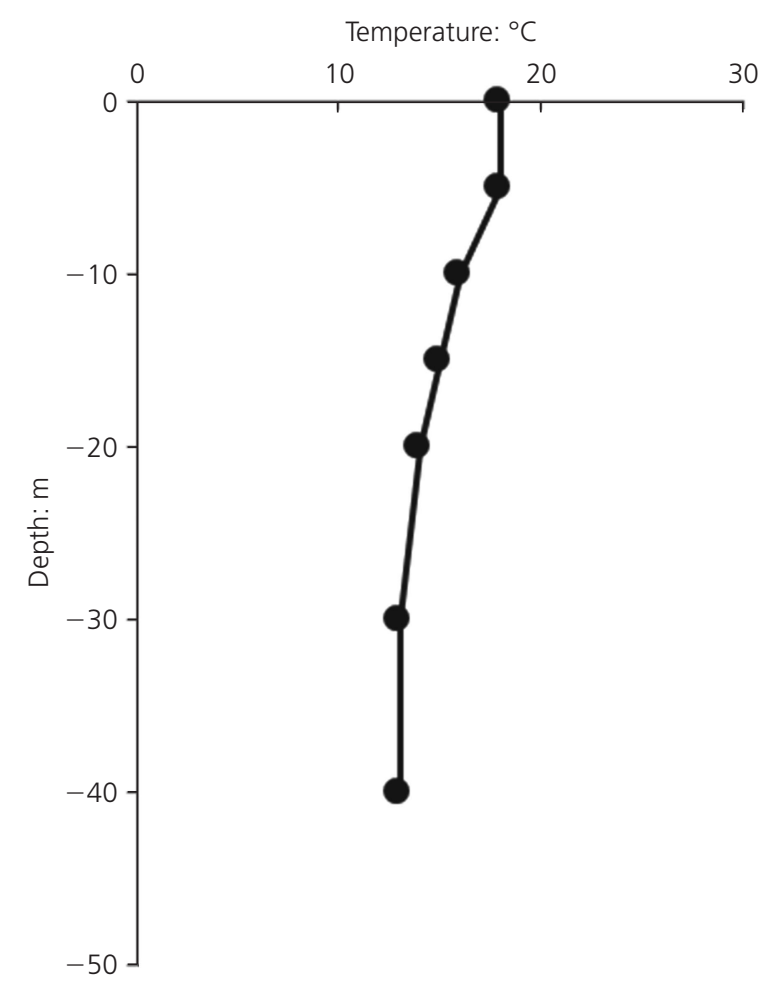

Figure 3. Initial condition for water temperature in reservoir (21/04/2008)

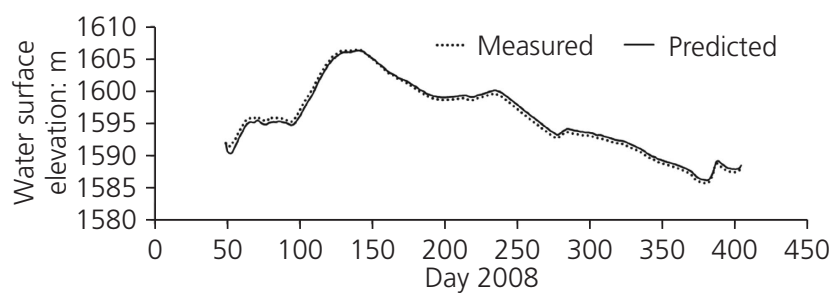

Figure 4. Comparison of the water surface elevation between measured and predicted data

In the next step we calibrated the coefficients affecting temperature that are given in Table 1 . The eddy viscosity and windsheltering coefficient directly affect hydrodynamics, which affect heat and constituent transport. The wind-sheltering coefficient is one of the most important parameters in temperature modelling and should be adjusted first. The W2N algorithm, which includes the effects of cross-shear from wind and from tributary or branch inflows, was used for vertical eddy viscosity computation. W2N is recommended for water bodies with deep sections that could be stratified. When applying the calibrated coefficients in the model the results showed that measured water temperature and predicted water temperature data were in close agreement (Figure 5). 


\section{Coefficient}

Calibrated value

Longitudinal eddy viscosity

Longitudinal eddy diffusivity

Vertical eddy viscosity algorithm

$1 \mathrm{~m}^{2} / \mathrm{s}$

$1 \mathrm{~m}^{2} / \mathrm{s}$

W2N

0.8

$0 \cdot 45$

Solar radiation absorbed in surface layer

Extinction coefficient for pure water

$0.45 / \mathrm{m}$

Table 1. Coefficients affecting thermal calibration

The calibrated model needs to be validated in order to test that the model is able to simulate the hydrodynamic and thermal structure of the reservoir under different conditions. Field data collected in 2009 were used to validate the model. It should be mentioned that the inflow conditions in 2009 were different from those in 2008, the year used for model calibration purposes. Figure 6 represents the validation results, which imply that there is reasonable agreement between the model results and field data. The values of the mean absolute relative error (RE) for calibration and verification purposes were $3.5 \%$ and $5 \cdot 2 \%$, respectively. These values are in line with the results of the review research conducted by Arhonditsis and Brett (2004). Hence, the validated model can be used to predict the Latian reservoir response to climate change scenarios.

\subsection{Generating scenarios}

One of the most important environmental concerns that threaten the water ecosystem is climate change due to global warming. The 2000-2100 daily temperature data for the special report on emissions scenarios A2, A1B and B2 of the intergovernmental panel on climate change (IPCC) were adopted for future climate conditions. In this study, the year 2100 represents the future
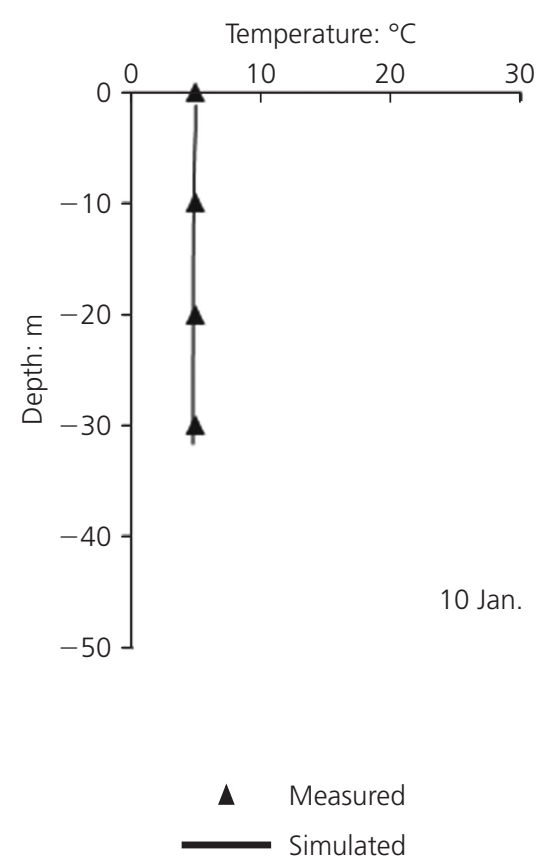
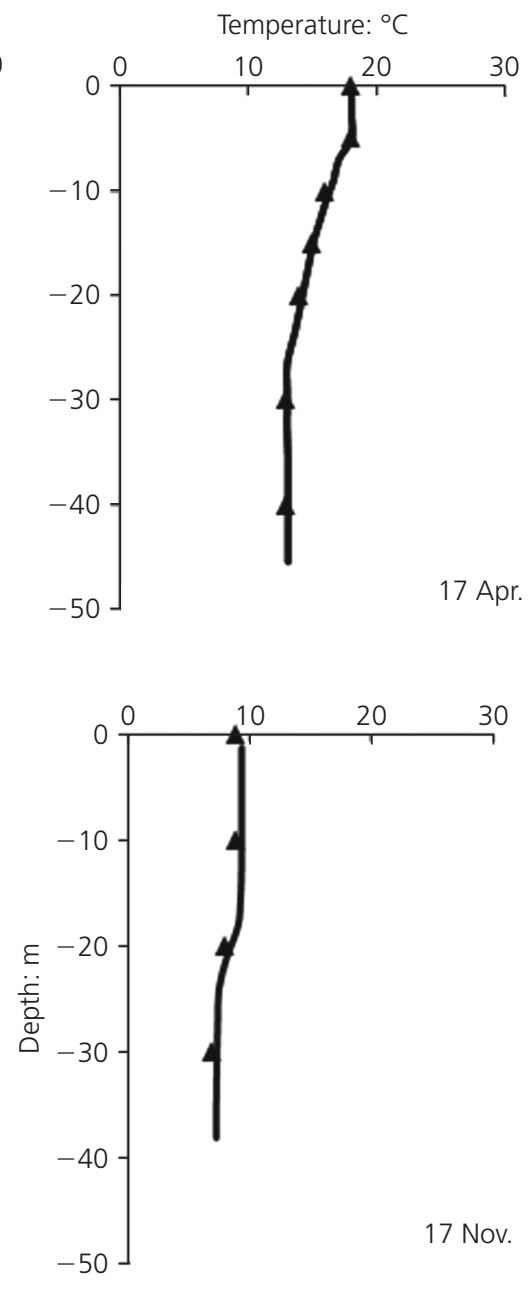
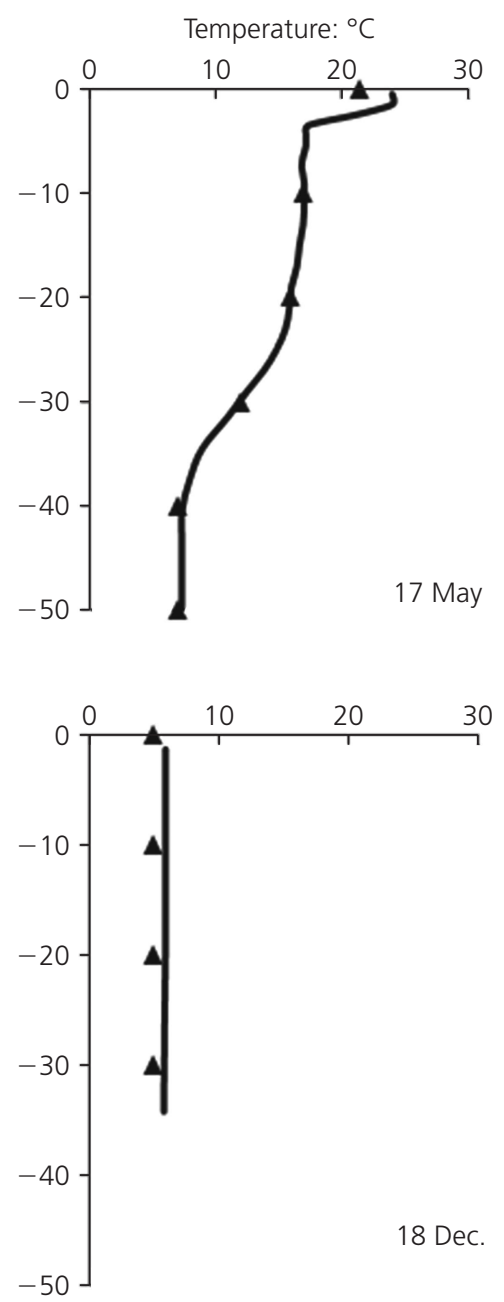

Figure 5. Comparison between the measured and simulated temperature profiles, calibration period 

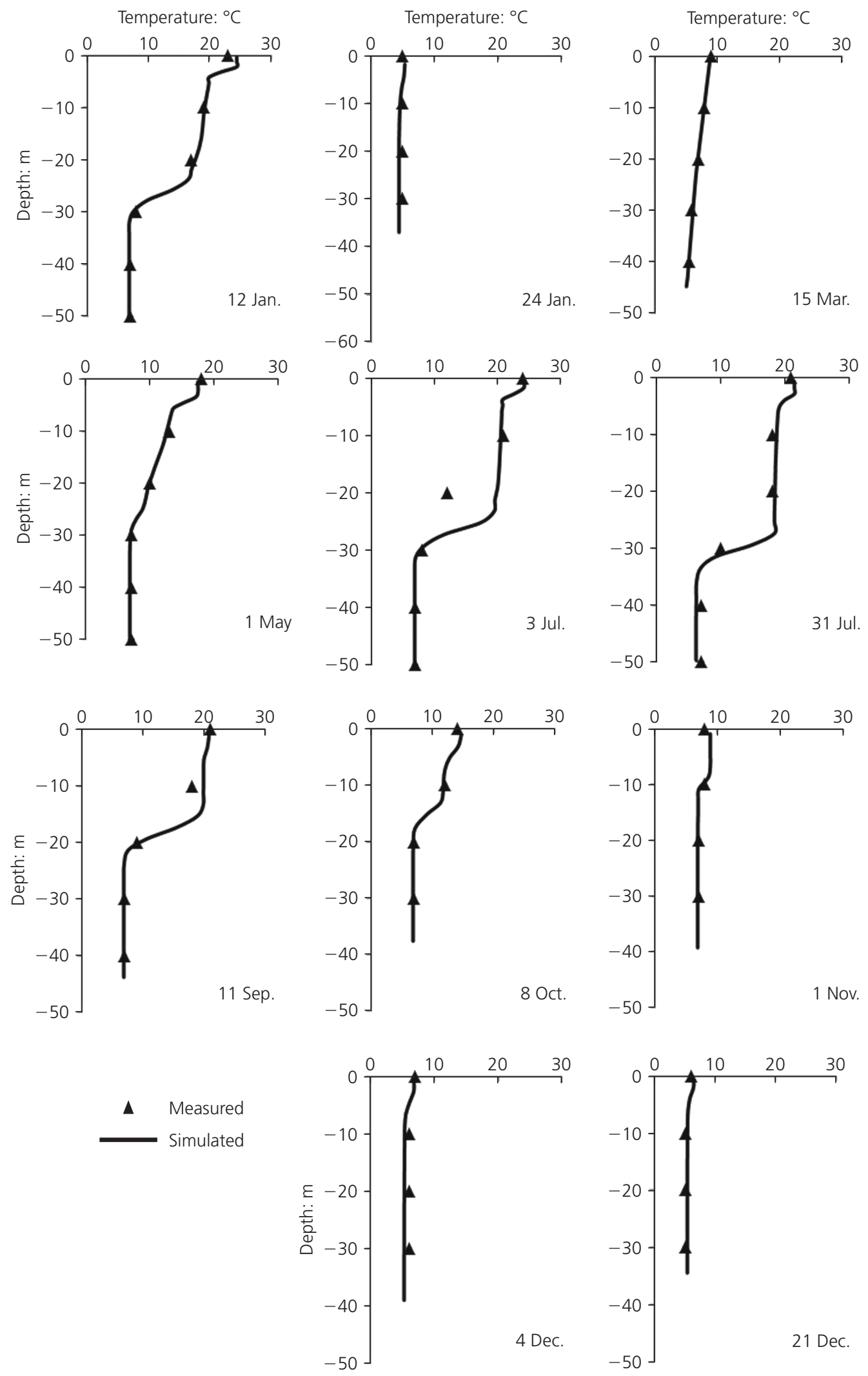

Figure 6. Comparison between the measured and simulated temperature profiles, verification period 
condition. It is assumed that the mean annual air temperature at the Latian site for $\mathrm{A} 2, \mathrm{~A} 1 \mathrm{~B}$ and $\mathrm{B} 2$ would increase by $5 \cdot 7^{\circ} \mathrm{C}$, $3 \cdot 8^{\circ} \mathrm{C}$ and $2 \cdot 4^{\circ} \mathrm{C}$, respectively, in 2100 . Considering the geographical location of Latian dam ( $\left.35^{\circ} 47^{\prime} 24^{\prime \prime} \mathrm{N} ; 51^{\circ} 40^{\prime} 48^{\prime \prime} \mathrm{E}\right)$, air temperature values of the closest cellule in the IPCC grid were obtained from IPCC in 2100. Figure 7 indicates the increasing air temperature trend for the A2 scenario (2000-2100). The air temperatures of 2100 for these scenarios were used to estimate the inflow water temperatures using the historical relationship between air temperature and inflow water temperature (water

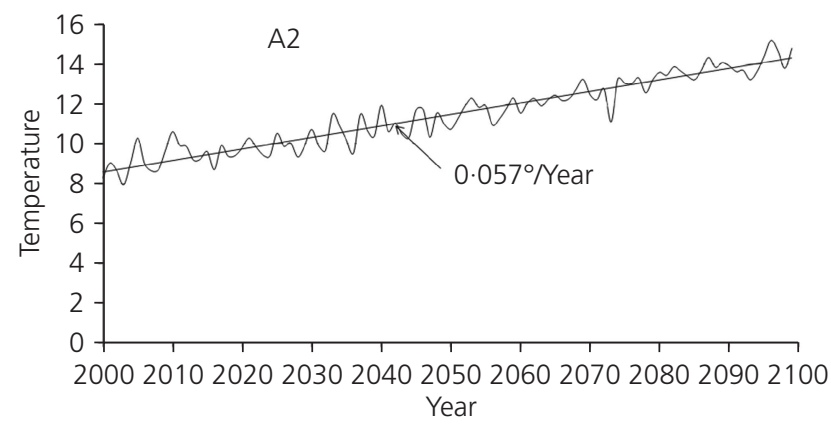

Figure 7. Temperature increasing trend for $\mathrm{A} 2$ scenario temperature $=0.97 \times$ air temperature $+0 \cdot 38$ ). Considering different inflow conditions and air temperature variations, 21 scenarios were generated for Latian dam reservoir, which are shown in Table 2. In the scenarios generated, three different inflow conditions were considered to analyse the sensitivity of thermal stratification to inflow variations. Then, these three base conditions were compared to the same conditions after applying different scenarios. According to the findings of Ficklin et al. (2013) and Ye et al. (2011), a 10\% decrease was assumed for inflow rates. Ficklin et al. (2013) found that there will be 5\% and $11 \%$ decreases in annual stream flow for the A2 scenario, in 2050 and 2080, respectively. Ye et al. (2011) reported that in a catchment with a subtropical wet climate, inflow will decrease by $5 \cdot 2 \%$ in 2050 in the A2 scenario. These three inflow conditions included low water inflow, high water inflow and the low outflow condition, which led to a high water elevation in the dam. The average inflow rate was $6.79 \mathrm{~m}^{3} / \mathrm{s}$ in 2009 , which represents a low water inflow condition. In 2003, which was a high flow water condition (wet year), the average inflow rate was $21.63 \mathrm{~m}^{3} / \mathrm{s}$. In 2002, the reservoir experienced the average water elevation of $1606.22 \mathrm{~m}$, which was the highest value during the reservoir's lifetime, and, in this year, the average inflow rate was $13.45 \mathrm{~m}^{3} / \mathrm{s}$. In addition, three climate change scenarios (A2, A1B and B1) were used to analyse thermal stratification sensitivity to temperature variations.

\begin{tabular}{cll}
\hline Condition & $\begin{array}{c}\text { Scenario Inflow variation } \\
\text { name }\end{array}$ & $\begin{array}{l}\text { Air temperature } \\
\text { variation }\end{array}$
\end{tabular}

\begin{tabular}{llll}
\hline Low water inflow & S1 & Decreasing $(10 \%)$ & Constant \\
(dry) condition (2009) & S2 & Constant & Increasing $\left(5 \cdot 7^{\circ} \mathrm{C}\right)$ \\
& S3 & Constant & Increasing $\left(3 \cdot 8^{\circ} \mathrm{C}\right)$ \\
& S4 & Constant & Increasing $\left(2 \cdot 4^{\circ} \mathrm{C}\right)$ \\
& S5 & Decreasing $(10 \%)$ & Increasing $\left(5 \cdot 7^{\circ} \mathrm{C}\right)$ \\
& S6 & Decreasing $(10 \%)$ & Increasing $\left(3 \cdot 8^{\circ} \mathrm{C}\right)$ \\
& S7 & Decreasing $(10 \%)$ & Increasing $\left(2 \cdot 4^{\circ} \mathrm{C}\right)$ \\
High water inflow & S8 & Decreasing $(10 \%)$ & Constant \\
(wet) condition & S9 & Constant & Increasing $\left(5 \cdot 7^{\circ} \mathrm{C}\right)$ \\
(2003) & S10 & Constant & Increasing $\left(3 \cdot 8^{\circ} \mathrm{C}\right)$ \\
& S11 & Constant & Increasing $\left(2 \cdot 4^{\circ} \mathrm{C}\right)$ \\
& S12 & Decreasing $(10 \%)$ & Increasing $\left(5 \cdot 7^{\circ} \mathrm{C}\right)$ \\
& S13 & Decreasing $(10 \%)$ & Increasing $\left(3 \cdot 8^{\circ} \mathrm{C}\right)$ \\
& S14 & Decreasing $(10 \%)$ & Increasing $\left(2 \cdot 4^{\circ} \mathrm{C}\right)$ \\
High water elevation & S15 & Decreasing $(10 \%)$ & Constant \\
condition $(2002)$ & S16 & Constant & Increasing $\left(5 \cdot 7^{\circ} \mathrm{C}\right)$ \\
& S17 & Constant & Increasing $\left(3 \cdot 8^{\circ} \mathrm{C}\right)$ \\
& $\mathrm{S} 18$ & Constant & Increasing $\left(2 \cdot 4^{\circ} \mathrm{C}\right)$ \\
& $\mathrm{S} 19$ & Decreasing $(10 \%)$ & Increasing $\left(5 \cdot 7^{\circ} \mathrm{C}\right)$ \\
& $\mathrm{S} 20$ & Decreasing $(10 \%)$ & Increasing $\left(3 \cdot 8^{\circ} \mathrm{C}\right)$ \\
& $\mathrm{S} 21$ & Decreasing $(10 \%)$ & Increasing $\left(2 \cdot 4^{\circ} \mathrm{C}\right)$
\end{tabular}

Table 2. Different scenarios used 
In some scenarios ( $\mathrm{S} 1, \mathrm{~S} 8, \mathrm{~S} 15)$, air temperature was maintained constant and inflow rates were decreased by $10 \%$. In some other scenarios (S2, S3, S4, S9, S10, S11, S16, S17, S18), the inflow rates were kept constant and climate change scenarios were applied. Finally, in the remaining scenarios (S5, S6, S7, S12, S13, S14, S19, S20, S21), both air temperature and inflow rates were varied simultaneously. Then the effects of these scenarios on the Latian dam reservoir were investigated.

\section{Results and discussion}

The results of this research indicated that an increase in air temperature would lead to an increase in the lake's temperature (Figure 8). When inflow water temperature increases due to an increase in air temperature, water temperature increases at different depths of the dam. In addition, simulations using different initial temperature profiles demonstrated that the final results are the same after about 2 weeks. Different scenario results are shown in Table 3.

When applying the climate change scenarios and keeping the inflow rates constant, it was found that future climate change would impact thermal stratification. Analysis of different scenario results showed the strongest effects on thermal stratification in the S2 scenario (among S2, S3, S4, S9, S10, S11, S16, S17 and $\mathrm{S} 18)$. This result was not far from expectations because in this scenario the increase in temperature was higher in comparison

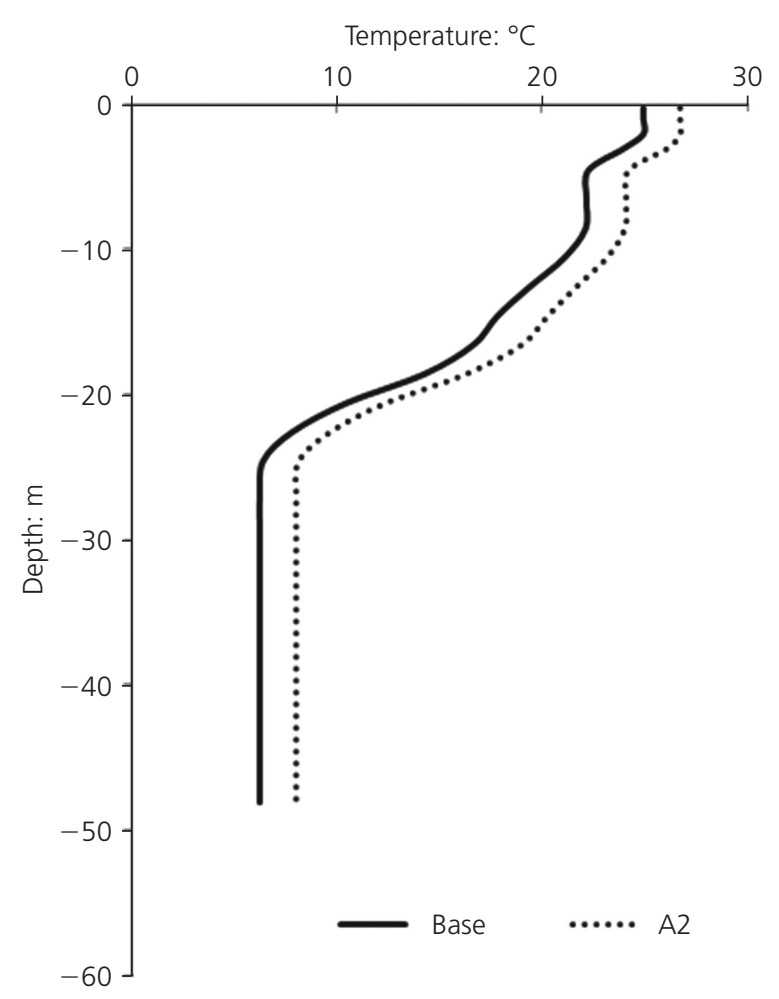

Figure 8. Increase in water temperature on 23 July 2100

\begin{tabular}{|c|c|c|c|}
\hline Condition & $\begin{array}{l}\text { Scenario } \\
\text { name }\end{array}$ & $\begin{array}{l}\text { Thermal stratification } \\
\text { period changes }\end{array}$ & $\begin{array}{c}\text { Average increase in } \\
\text { surface temperature: }{ }^{\circ} \mathrm{C}\end{array}$ \\
\hline \multirow{7}{*}{$\begin{array}{l}\text { Low water inflow } \\
\text { (dry) condition (2009) }\end{array}$} & S1 & Unchanged & $<1$ \\
\hline & $\mathrm{S} 2$ & 20-day increased & 1.92 \\
\hline & S3 & 〜20-day increased & 1.73 \\
\hline & S4 & 〜20-day increased & $1 \cdot 29$ \\
\hline & S5 & 40-day increased & $3 \cdot 1$ \\
\hline & S6 & 30-day increased & $2 \cdot 11$ \\
\hline & S7 & 30-day increased & 1.68 \\
\hline \multirow{7}{*}{$\begin{array}{l}\text { High water inflow } \\
\text { (wet) condition } \\
\text { (2003) }\end{array}$} & S8 & Unchanged & $<1$ \\
\hline & s9 & 1-week increased & $1 \cdot 81$ \\
\hline & S10 & $\sim 1$-week increased & $1 \cdot 37$ \\
\hline & S11 & $\sim 1$-week increased & $1 \cdot 10$ \\
\hline & $\mathrm{S} 12$ & 10-day increased & $2 \cdot 19$ \\
\hline & S13 & 10-day increased & 1.46 \\
\hline & S14 & 10-day increased & $1 \cdot 19$ \\
\hline \multirow{7}{*}{$\begin{array}{l}\text { High water elevation } \\
\text { condition (2002) }\end{array}$} & S15 & Unchanged & $<1$ \\
\hline & S16 & 1-week increased & 1.91 \\
\hline & S17 & $\sim 1$-week increased & 1.65 \\
\hline & S18 & $\sim 1$-week increased & $1 \cdot 18$ \\
\hline & S19 & 10-day increased & $2 \cdot 25$ \\
\hline & S20 & 10-day increased & 1.72 \\
\hline & S21 & 10-day increased & 1.46 \\
\hline
\end{tabular}

Table 3. Different scenario results 
with those of other scenarios, and the reservoir was in a low water flow condition. In these scenarios, the increase in temperature was the same at different depths of the reservoir hence the thermal gradient remained unchanged (Figure 8). The maximum value of the increase in water surface temperature was about $2^{\circ} \mathrm{C}$, which was obtained for the S2 scenario. These results are in line with those of Sahoo and Schladow (2008) and Lee et al. (2012). Lee et al. (2012) found that in Yangdam Reservoir, located in the Asian monsoon area, with a $4 \cdot 2^{\circ} \mathrm{C}$ rise in air temperature, the water temperature increase in 2090 is expected to be $2 \cdot 2^{\circ} \mathrm{C}$ in the epilimnion and $0.6^{\circ} \mathrm{C}$ in the hypolimlion. An obvious difference in the values of water and air specific heat can be one of the reasons why air temperature increases more than water temperature. This is a very important feature because it allows the large bodies of water on the earth's surface to moderate the climate. In addition, lake morphometry is one of the most important parameters in warming and cooling trends of lakes. Surface water temperature is a useful index of climate change because meteorological variables are reflected by it more immediately and more sensitively than any other lake parameters. Considering this fact, lakes are direct and immediate responders to increases in air temperature. The surface water is exposed to solar radiation and long-wave radiation of the atmosphere. Lake morphometry is one of the most important parameters in the increasing and decreasing trends of the hypolimnetic temperature. In addition, seasonal changes play an important role in this process. The considerable increase in water temperature has significant effects on thermal stratification. The onset time of thermal stratification was earlier in these scenarios and it was more stable than those in 2009, 2003 and 2002, which represent the base years for three different inflow conditions. In other words, the thermal stratification period was increased in all conditions.

As mentioned previously, in scenarios with inflow variation, the inflow rates were decreased by $10 \%$ to evaluate thermal stratification response to inflow variations. In scenarios $\mathrm{S} 1, \mathrm{~S} 8$ and $\mathrm{S} 15$, when the inflow rates were decreased by $10 \%$ and the temperature was kept constant, it was found that the thermal gradient in thermocline increased because the increase in thermocline temperature was greater than that of the hypolimnion temperature. The thermal stratification period remained nearly unchanged because the vertical disturbance is affected by water flow and wind; a slight decrease in inflow rates does not change thermal stratification significantly. This is in close agreement with the findings of Rimmer et al. (2011) in their investigation on Lake Kinneret thermal stratification.

When the last scenarios, with simultaneous temperature and inflow rate changes, were applied, the maximum change in thermal stratification was observed. In these scenarios, the increase in epilimnion temperature was more than that of hypolimnion. Therefore, it can be said that the thermal gradients in these scenarios are sharper than those of previous scenarios. Differences in epilimnion and hypolimnion temperatures in summer are greater than those in other seasons because of the highest air temperature in the summer. The increase in thermal gradient was
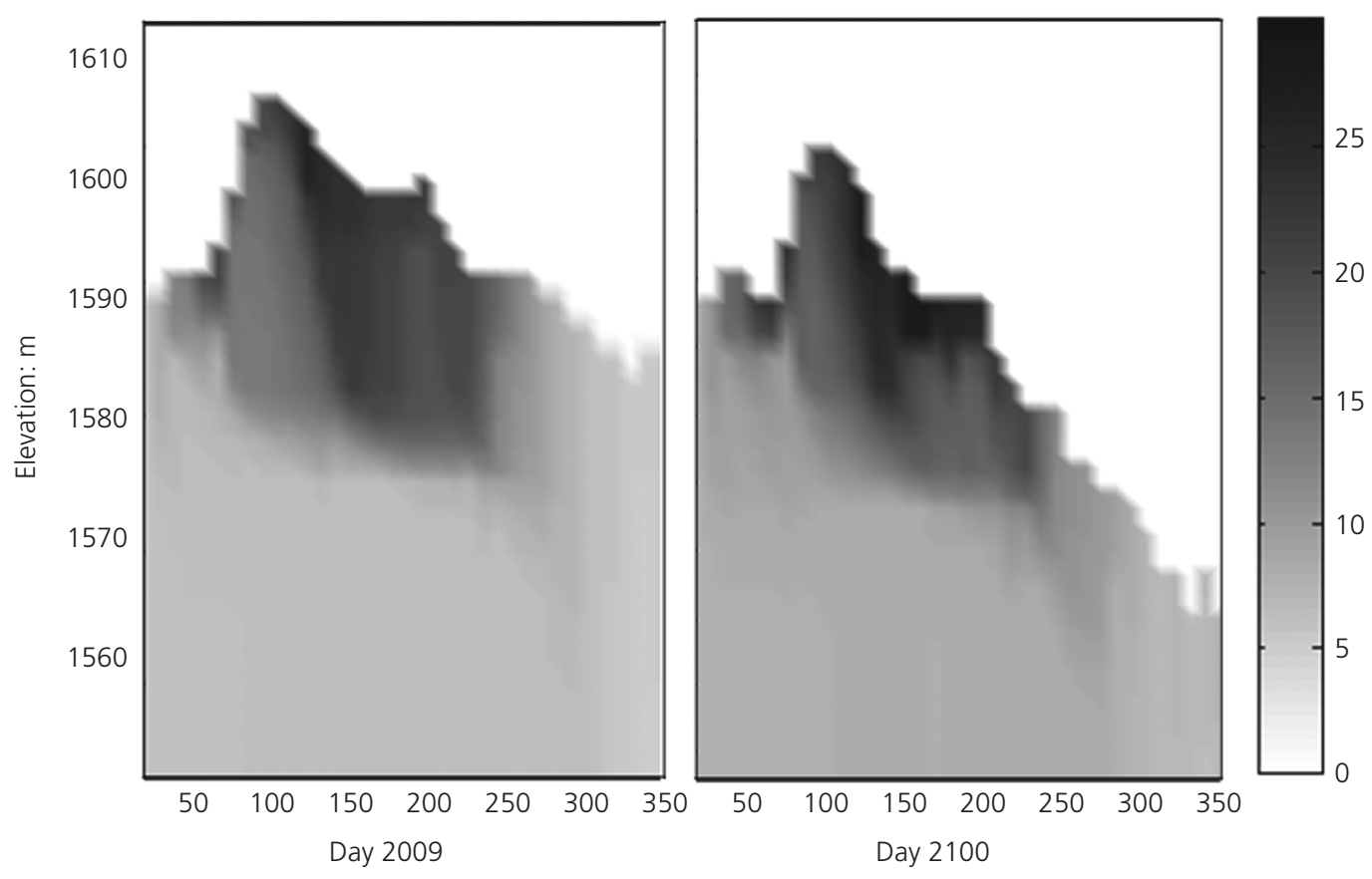

Figure 9. Differences in thermal structure in 2009 and 2100 


\section{Offprint provided courtesy of www.icevirtuallibrary.com Author copy for personal use, not for distribution}

more severe in the S5 scenario among all scenarios (Figure 9). The mean values of the temperature increase were predicted to be $3^{\circ} \mathrm{C}$ in epilimnion and $1^{\circ} \mathrm{C}$ in hypolimnion. The thermal stratification period increased in these scenarios especially in scenario S5. The lengths of the stratification period, with $15^{\circ} \mathrm{C}$ differences between surface and bottom waters, were predicted to be 130 days during 2009 and 170 days during 2100. This might be caused by a decrease in inflow rates, which play an important role in mixing the water column. The onset of the thermal stratification period, with $15^{\circ} \mathrm{C}$ differences between surface and bottom waters during 2100, is 50 days earlier than that of 2009 . Furthermore, the value of the lake number was increased by more than $25 \%$ in the S5 scenario. This indicates a more stratified lake in the future, which may change the oxygen and metal levels in the bottom layers as well as the chlorophyll level of the surface layer (Robertson et al., 1990).

The modelling study of the effects of increasing air temperature on the thermal structure of the Latian dam showed consistent results with those of previous studies, in terms of greater temperature increases in the epilimnion than in the hypolimnion and increased thermal stratification (Fang and Stefan, 2009; Komatsu et al., 2007; Lee et al., 2012; Sahoo and Schladow, 2008; Wang et al., 2012). Lee et al., 2012 investigated the effect of climate change on the thermal structure of lakes in response to watershed hydrology. They found that increases in air temperature resulted in higher surface water temperature. The simulation of the effects of climate warming on the thermal structure of the Asian monsoon area lake showed greater temperature increases in the epilimnion than in the hypolimnion, increased thermal stratification and decreased thermocline depths during the summer and autumn. The results were in harmony with the findings of earlier research conducted by Komatsu et al. (2007). In their study, a GCMA2 scenario was applied to Shimajigawa Reservoir located in western Japan in order to assess the long-term effect of global warming on environmental variables. Also, Wang et al. (2012) used a numerical model to create scenarios incorporating different air temperatures, inflow volumes and water levels in Liuxihe Reservoir, southern China. Under continuous warming and more stable storage in recent years, the simulations indicated greater water column stability and increased stratification duration. Moreover, research on Lake Tahoe was conducted by Sahoo and Schladow (2008) in order to evaluate the impact of climate change on the physical processes occurring within lakes. Results of 40-year simulations showed that the lake continued to become warmer and more stable. Also, it was concluded that circulation in the lake was reduced. It was predicted that in low water flow conditions, when applying the S5 scenario, thermocline depth increased $3 \mathrm{~m}$ in August and September by 2100. However, in high flow conditions, thermocline depth remained unchanged by 2100 .

When the epilimnetic and hypolimnetic water temperatures become the same, turnover due to surface cooling occurs in the reservoir. After this period of water mixing, the surface water temperature rises with sun radiation and thermal stratification grows. In the Latian reservoir, turnover took place at the end of December in 2009, which was estimated to occur 2 weeks later by applying the $\mathrm{S} 5$ scenario. The important point to mention here is that deep mixing occurs only during winter. In fact, the results of this study suggest that Latian reservoir water quality should be monitored more frequently in future years because of changing climate and varying hydrological conditions.

\section{Summary and conclusion}

Recently, climate change and its potential effects on water quality and quantity in global scale to local scale is one of the most important challenges to be faced. Normally, climate change studies are based on meteorological model outputs under emissions scenarios fed into simulation models (hydrological, hydrodynamic and water quality models). In this study, the effect of temperature variation due to climate change on the thermal stratification of Latian dam reservoir was investigated. The CE-QUAL-W2 model was used to simulate Latian dam reservoir. Then 21 scenarios were generated to analyse the response of Latian dam to temperature and inflow rate variations.

The results showed that the thermal stratification of Latian dam reservoir is very sensitive to air temperature and inflow rate variations. In the scenarios with constant flow and increasing temperature, it was found that an increase in air temperature has a significant effect on the onset time of thermal stratification as it will occur earlier and thermal stratification will last longer.

Scenarios with decreasing inflow and constant temperature led to an increase in thermocline thermal gradient and unchanged thermal stratification period. An increase in thermal gradient in low water flows was greater than in other conditions. In scenarios with changing temperature and inflow rates simultaneously, it was found that the thermal gradient is sharper in comparison with those of other scenarios. An increase in the thermal gradient was more severe in the S5 scenario among all scenarios in which temperature and inflow rates were changed simultaneously. The mean value of temperature increase was $3^{\circ} \mathrm{C}$ in epilimnion and $1^{\circ} \mathrm{C}$ in hypolimnion.

It was predicted that by 2100 , the length of the stratification period with a $15^{\circ} \mathrm{C}$ difference between the surface and bottom water layer temperature will be 40 days more than that of the base year 2009. The thermal stratification period in 2100 occurs 50 days earlier than that of the base year. Furthermore, it was predicted that thermocline depths in these scenarios will change especially in low flow conditions. However, in high flow conditions, thermocline depth remains unchanged in 2100 .

The results of this study can be used in future investigations of the effects of climate change on the water quality and ecosystem 
of Latian dam reservoir, and potentially provides useful information for better water resources management.

\section{Acknowledgements}

The authors would like to acknowledge Ms Motahareh Saadatpour and Mr Ali Behnood for their review and comments.

\section{REFERENCES}

Afshar A, Saadatpour M and Marino MA (2012) Development of a complex system dynamic eutrophication model: application to Karkheh reservoir. Environmental Engineering Science 29(6): $373-385$.

Arhonditsis GB and Brett MT (2004) Evaluation of the current state of mechanistic aquatic biogeochemical modeling. Marine Ecology Progress Series 271: 13-26.

Bates B, Kundzewicz ZW, Wu S and Palutikof J (2008) Climate Change and Water. Technical Paper of the Intergovernmental Panel on Climate Change. IPCC Secretariat, Geneva, Switzerland, pp. 210.

Branco CWC, Kozlowsky-Suzuki B, Sousa-Filho IF, Guarino AWS and Rocha RJ (2009) Impact of climate on the vertical water column structure of Lajes Reservoir (Brazil): a tropical reservoir case. Lakes \& Reservoirs: Research \& Management 14(3): 175-191.

Cole TM and Wells SA (2003) CE-QUAL-W2: A Two-dimensional, Laterally Averaged, Hydrodynamic and Water Quality Model, Version 3.2. US Army Engineering and Research Development Center, Vicksburg, MS, USA, Instruction Report EL-03-1.

Dai L, Dai H and Jiang D (2012) Temporal and spatial variation of thermal structure in Three Gorges Reservoir: a simulation approach. Journal of Food, Agriculture \& Environment 10(2): 1174-1178.

Etemad-Shahidi A, Afshar A, Alikia H and Moshfeghi H (2009) Total dissolved solid modeling: Karkheh Reservoir case example. International Journal of Environmental Research 3(4): $671-680$.

Fang X and Stefan HG (2009) Simulations of climate effects on water temperature, dissolved oxygen, and ice and snow covers in lakes of the contiguous United States under past and future climate scenarios. Limnology and Oceanography 54(6): 2359-2370.

Ficklin DL, Stewart IT and Maurer EP (2013) Effects of projected climate change on the hydrology in the Mono Lake Basin, California. Climatic Change 116(1): 111-131.

Garvey E, Tobiason JE, Hayes R et al. (1998) Coliform transport in a pristine reservoir: modeling and field studies. Water Science and Technology 37(2): 137-144.

Hasanloo D and Etemad-Shahidi A (2011) On the estimation of transport timescales - case study: the Dez reservoir. Journal of Hydro Informatics 13(2): 217-228.

Hordoir R and Meier HEM (2012) Effect of climate change on the thermal stratification of the Baltic sea: a sensitivity experiment. Climate Dynamics 38(9-10): 1703-1713.

IPCC (2001) (Intergovernmental Panel on Climate Change)
Climate Change 2001: The Scientific Basis. Contribution of Working Group I to the Third Assessment Report of the Intergovernmental Panel on Climate Change. Cambridge University Press, Cambridge, UK and New York, NY, USA, pp. 881, see http://www.ipcc.ch/ (accessed 20/10/2013).

Johns TC, Gregory JM, Ingram WJ et al. (2003) Anthropogenic climate change for 1860 to 2100 simulated with the HadCM3 model under updated emissions scenarios. Climate Dynamics 20(6): 583-612.

Komatsu E, Fukushima T and Harasawa H (2007) A modeling approach to forecast the effect of long-term climate change on lake water quality. Ecological Modeling 209(2-4): 351366.

Lee HY, Kim EJ, Park SS and Choi GH (2012) Effects of climate change on the thermal structure of lakes in the Asian monsoon area. Climate Change 112(3): 859-880.

Martin JL (1988) Application of two-dimensional water quality model. Journal of Environmental Engineering 114(2): $317-$ 336.

Moreno-Ostos E, Marce R, Ordonez J, Dolz J and Armeng J (2008) Hydraulic management drives heat budgets and temperature trends in a Mediterranean reservoir. International Review Hydrobiology 93(2): 131-147.

Parsa J and Etemad-Shahidi A (2010) Prediction of tidal excursion length in estuaries due to the environmental changes. Journal of Environmental Science International 7(4): $675-686$.

Rangel-Peraza JG, Obregon O, Nelson J et al. (2012) Modeling approach for characterizing thermal stratification and assessing water quality for a large tropical reservoir. Lakes \& Reservoirs: Research \& Management 17(2): 119-129.

Rimmer A, Gal G, Opher T and Lechinsky Y (2011) Mechanisms of long-term variations in the thermal structure of warm lake. Limnology \& Oceanography 56(3): 974-988.

Robertson DM, Imberger J and Boland K (1990) Lake number: an indicator of reservoir mixing: a water quality management tool. Water (AWWA Journal) December: 29-33.

Sahoo GB and Schladow SG (2008) Impacts of climate change on lakes and reservoirs dynamics and restoration policies. Sustainability Science 3(2): 189-199.

Tillman DH and Cole TM (1994) Bluestone Phase 2 Temperature and Dissolved Oxygen Modeling Study. Environmental Lab, Army Engineer Waterways Experiment Station, Vicksburg, MS, USA.

Trolle D, Hamilton DP, Pilditch CA, Duggan IC and Jeppesen E (2011) Predicting the effects of climate change on trophic status of three morphologically varying lakes: implications for lake restoration and management. Environmental Modelling \& Software 26(4): 354-370.

Wang S, Qian X, Han BP, Luo LC and Hamilton DP (2012) Effects of local climate and hydrological conditions on the thermal regime of a reservoir at Tropic of Cancer, in southern China. Water Research 46(8): 2591-2604.

Welch EB and Jacoby JM (2001) On determining the principal 
source of phosphorus causing summer algal blooms in western Washington lakes. Journal of Lake \& Reservoir Management 17(1): 55-65.

Wetzel RG (2001) Limnology, Lake and River Ecosystems. Academic Press, San Diego, CA, USA.

Ye X, Zhang Q, Bai L and Hu Q (2011) A modeling study of catchment discharge to Poyang Lake under future climate in China. Quaternary International 244(2): 221-229.

Zahed F, Etemad-Shahidi A and Jabbari E (2008) Modeling of salinity intrusion under different hydrological conditions in the Arvand River Estuary. Canadian Journal of Civil Engineering 35(12): 1476-1480.

\section{WHAT DO YOU THINK?}

To discuss this paper, please email up to 500 words to the editor at journals@ice.org.uk. Your contribution will be forwarded to the author(s) for a reply and, if considered appropriate by the editorial panel, will be published as a discussion in a future issue of the journal.

Proceedings journals rely entirely on contributions sent in by civil engineering professionals, academics and students. Papers should be 2000-5000 words long (briefing papers should be 1000-2000 words long), with adequate illustrations and references. You can submit your paper online via www.icevirtuallibrary.com/content/journals, where you will also find detailed author guidelines. 